\title{
Fantomas urbanos: cuerpos vigilados - calles retratadas ${ }^{1}$
}

\section{Urban Machine: Guarded Bodies - Portrayed Streets}

\author{
Lorena Antezana Barrios \\ Universidad de Chile, Chile \\ lorena.antezana@gmail.com
}

\author{
Carlos Ossa Swears \\ Universidad de Chile, Chile \\ anis626@yahoo.es
}

Resumen - Las primeras fotografías de ciudad tomadas en Chile, inicialmente por viajeros extranjeros, pueden ser leídas como el diseño espacial de una estrategia de ordenamiento sociopolítico. El análisis que proponemos en este artículo intenta interpelar la neutralidad de la técnica fotográfica al poner en evidencia la primacía de la mirada que capta y diseña al objeto dentro de las luchas simbólicas del Estadonación. En ese sentido, la fotografía contribuye a difundir una hegemonía flexible cuya puesta en escena propone una jerarquización arquitectónica y visual de los territorios iluminados y solemnes donde reposan la autoridad y sus valores. La modernización impone nuevas anatomías ópticas a una ciudad que se levanta del pasado colonial para recibir el progreso con sus disciplinas laborales y seducciones estéticas.

Palabras clave: fotografía, ciudad, visualidad, espacio, orden.

Abstract - The first city photographs taken in Chile, initially by foreign travelers, could be read as the spatial design of a sociopolitical strategy. The analysis proposed in this article tries to deal with the neutrality of the photographic technique by highlighting the priority of sight that captures and designs the object within the symbolic struggles of the Nation-state. In this regard, photography allows disseminating a flexible hegemony. Its staging proposes a visual and architectonical hierarchy in the illuminated and solemn territories where authority and values lie down. Modernization imposes new optical anatomies to a city that rises from the colonial past to receive progress with their work disciplines and aesthetic seductions.

Keywords: Photography, City, Visuality, Space, Order.

$1 \quad$ El presente artículo se basa en el análisis de un corpus de 487 fotos correspondientes al periodo comprendido entre 1840 y 1930. Las fotografías son parte de las colecciones patrimoniales disponibles en Chile en el Catálogo del Centro del Patrimonio Fotográfico CENFOTO bajo las rúbricas de ciudad y urbano. El método de análisis utilizado es fenomenológico, intentando realizar una lectura transversal, plural y abierta del corpus relacionándolo con perspectivas sociohistóricas y territoriales del periodo considerado. Por esta razón se hizo necesario volver al contexto etnográfico, pues los soportes visuales, al permitirnos inteligibilizar los imaginarios simbólicos que hablan a través del texto, nos reenvían a las categorías de pensamiento cultural de los sujetos sociales. 
En 1840 llega a Chile un instrumento mecánico destinado a occidentalizar la memoria; han pasado solo treinta y tres años desde la independencia y la fotografía se convierte en parte de un nuevo régimen de visibilidad política asociado a la formación del Estadonación. ¿Quiénes son los protagonistas? ¿Cuál es su modelo de referencia? La sociedad patricia comienza a separarse de ideologías testamentarias para abrazar la emulsión y el nitrato de plata, esperando encontrar en ellas la validación modernista junto con la abnegación religiosa. Sin embargo, el modelo propuesto debe conciliar los remanentes simbólicos de los colonizadores españoles con los contenidos de una episteme cultural imperante que responde a lo que Souza de Santos denomina «sociología de las ausencias», es decir, una vaciedad institucional incapaz de construir el otro del poder, lo que podría explicar por qué la totalidad sigue siendo la de un cristianismo corporativo, administrado por una oligarquía ociosa protegida por una milicia emergente. Así se mantiene una racionalidad burocrático-mesiánica durante el periodo que transcurre desde la independencia al Centenario y pone en evidencia el tipo de ocupación territorial, la circulación de prestigios y los derechos exclusivos de imagen. A pesar de ser la misma conciencia colonial, esta viene revestida con los ropajes de un liberalismo político que necesita nuevas dramaturgias que no pueden ser satisfechas con las viejas visualidades de un barroco monástico e imperial. Por ello, la fotografía no solo desplaza cierta iconicidad aristocratizante -sostenida por la pintura- sino que agrega una gestualidad modernizadora, promesa de integración y autoconciencia de clase. La imagen técnica es un punto de intersección -como señala Jonathan Crary- donde los discursos filosóficos, científicos, estéticos y clasistas encuentran una manera de convertirse en operaciones rituales, requerimientos institucionales y fuerzas socioeconómicas. El objeto material llamado fotografía cruza la vida social chilena generando condiciones para la aparición de una visión subjetiva y una visualidad racionalizante, en un caso lo fotografiado exhibe su «singularidad», en el otro, delata su «posición».

La fotografía, (al principio daguerrotipos), llega como novedad técnica a Chile de la mano de viajeros y aventureros de origen inglés y francés (Rodríguez 2001). Entre 1845 y 1860, los fotógrafos se instalan en las principales ciudades ofreciendo sus servicios a una sociedad cerrada que busca reforzar las distancias sociales mediante el acceso exclusivo a las imágenes. La foto de estudio destinada a dar coherencia al grupo familiar es la alegoría de la filiación, de la unidad interna y de la legitimidad moral de quienes tienen derecho a estar en la imagen por superioridad y tradición. Así, la fotografía, al menos en estos años de ensayo, no celebra una democratización de las clases, más bien refuerza esa obsesión histórica por delimitar las presencias y controlar las identidades. La nación es la familia, por ello el retrato de suelo y sangre se convierte en la representación de un nosotros que confunde lo privado y lo nacional en un solo texto. El Mercurio de Valparaíso lo expresa en 1879 de la siguiente manera:

¡Ah! La patria no es esa entidad que los cosmopolitas desprecian invocando al género humano; jah!, no, no es eso; la patria es todo, es cuna, sepultura de nuestros padres, familia, orgullo, pasado, presente, porvenir, en una palabra, el único objeto que desde que 
abrimos los ojos hasta que los cerramos para siempre no dejamos de amar un instante. Y esa patria, Chile, nuestro Chile querido, cuya historia, sin ser vieja ni muy voluminosa, encierra todos los prodigios de inmortal leyenda. Tierra de libertad, de hospitalidad cristiana, tierra de guerreros, de grandes ciudadanos, de mujeres heroicas (cit. en Cid 178).

Sin embargo, toda técnica trae consigo el cuestionamiento de un modelo representacional, y la fotografía, lentamente, se abre a la velocidad de los acontecimientos: al ruido insomne de valores afectados por imaginarios seculares y destinos económicos, accesibilidades materiales y represiones étnicas, mercantilización agraria pero también de lo sensible y cognitivo. La elite chilena -siempre en disputa-, por ajustar al príncipe cristiano con el tecnócrata liberal, requiere inventarse a sí misma y proyectar sobre el fondo oscuro del pasado un presente de conquistas, constituciones y ciudades: trilogía inevitable de toda empresa de dominación. Su símbolo de progreso y la forma de ilustrar su incorporación al capitalismo decimonónico es la organización racional de la ciudad.

La ciudad de Santiago necesita ser refundada en la imagen de su modernización y requiere medios técnicos acordes con un lenguaje de lo instantáneo y exhibitivo. El Estado Moderno reclama el control geográfico de un determinado territorio y construye su legitimidad a través de imágenes que han sido parte de su cuerpo político y le han dado su forma histórica. Organizar la mirada, definir las funciones y calcular el alcance de sus preceptos y leyes requiere una materialidad arquitectónica donde las cosas no se diluyan y donde se respeten las fronteras. La ciudad es el simulacro de la nación, ella exhibe la racionalidad desplegada sobre el conjunto anodino de historias, sujetos y épicas, usados en las leyendas de la patria. Los principales autores de esta concepción son geógrafos y gramáticos que imponen la cultura letrada con fuerza y sagacidad, pero nunca se ausentó una visualidad hecha de momentos básicos y obras complejas². Por ejemplo, el mayorazgo de Polpaico, José Antonio Rojas, parece haber introducido la cámara oscura al país, a fines del siglo XVIII; José Gil de Castro pudo usarla en la confección de los íconos nobiliarios de la guerra y la fortuna; Charles Wood y John Sarle consolidaron el concepto de paisaje, tan útil a las retóricas estatales posteriores; Mauricio Rugendas institucionalizó un canon visual que se impuso en el arte, la taxonomía y el archivo. De esta manera, lo visible se convierte en una necesidad para garantizar el orden. Orden que encuentra en lo visual no solo tramas, sino también sentidos para describir su propósito, el cual sería proponer un nuevo «régimen de la representación» (Tagg 19) de la realidad histórica en base a tres ejes: un origen, la ley natural que lo identifica como posible y esencial; un fundamento, la historia institucional que valida un modo de vivir juntos; y una utopía, el destino trascendental dado a una comunidad para alcanzar su fin. De esta suerte la visualidad justifica una estructura doble del poder: una investidura sacrificial-pastoral y otra coercitiva-disciplinaria.

El embajador de Chile en Francia, Francisco Javier Rosales, compró un daguerretipo y lo regaló al Instituto Nacional de Santiago para la enseñanza del arte y el dibujo. El aparato llegó con desperfectos y nunca puso usarse. 
El siglo xix latinoamericano reconoce la pulsión de la mirada y diseña un proceso de visibilidad que es paralelo con el orden que anuncia. La ciudad es una construcción simbólica que señala la ruta a la vida moderna basada en principios liberales tecnocráticos y costumbres ciudadanas normativas, pero solamente se es urbano cuando se ingresa a la imagen: ahí radica la fuerza del discurso visual. La industrialización de la fotografía permitió su rápida absorción en los usos racionales que rigen la sociedad. Las fotografías dejaron de ser imágenes de exhibición para:

formar parte del decorado general del ambiente, hitos y confirmaciones de esa aproximación reduccionista a la realidad que se considera realismo. Las fotografías fueron puestas al servicio de importantes instituciones de control, sobre todo la familia y la policía, como objetos simbólicos e informativos (Sontag 40).

La necesidad de validar el tránsito de la Colonia a la República exigió un sistema de representaciones capaz de articular un campo intelectual, una política cultural y una institucionalidad jurídica. El Estado se expandía mediante leyes y controles sociales pero debía capturar la obediencia y aceptación de sectores que no vivían en la letra y se sentían excluidos de los goces del progreso. Un régimen visual que los incluyera sin aceptarlos tenía la ventaja de disminuir el peligro a la rebelión o el asalto, a la vez que movilizaba símbolos de rápida adopción, fortaleciendo un sentimiento nacional cohesionante. Un poco antes que Víctor Daroche propusiera al gobierno de Manuel Montt la elaboración de un álbum de las ciudades chilenas -y con ello se justificara el rol de las elites en la conducción de un país actualizado y productivo-, Mauricio Rugendas elaboraba, para el Estado, diversas imágenes de la realidad, siendo el principal artífice de un mito corporal: el huaso, metáfora de rudeza y encarnación pastoral de la figura terrateniente, idilio entre la sangre de la tierra y la propiedad ancestral. Hay una visualidad fundacional anterior a la fotografía que se expande y consagra con ella desmintiendo el carácter estrictamente letrado del periodo.

De los muchos registros históricos, que permiten recrear la experiencia de la territorialidad, es la fotografía la que introduce un cambio sustantivo: transforma la geografía física en un objeto institucional. Enmarca el espacio en la clausura o bien lo circunscribe a una hermenéutica del orden, es decir, convierte esa imagen en un signo dramatúrgico mediante el cual el poder expresa su lugar. No es una voluntad encarnada, es solo la consecuencia de un proceso dialéctico: el hecho de que la reproductibilidad técnica es la política. De esta manera la imagen administra una ideología en la medida en que «la fotografía no es solo una porción de tiempo, sino de espacio» (Sontag 41).

\section{DIDÁCTICAS DE CALLE}

las historias no son telones de fondo para realzar la actuación de las imágenes. Se inscriben en los insignificantes signos de papel, en lo que hacen y lo que no hacen, en lo que abarcan y en lo que excluyan, en cómo se abren o cómo se resisten a un repertorio de usos en los que puedan ser significativos y productivos (Tagg 87). 
La imagen fotográfica adquiere, en la sociedad chilena del siglo xıx, una función antropológica-jurídica, otra estético-social y otra económica-pedagógica al inventar la escena de un sujeto que exige ser presentado con sus propiedades simbólicas y materiales como la identidad nacional y la singularidad modernista, encarnando la condición de persona y nación en un solo gesto edípico y narcisista: el triunfo liberal sobre el principio de realidad y la constitución de un nosotros escenográfico. La complejidad de esta tarea implica dar forma a una cultura donde se puedan resolver o reprimir las contradicciones a través de la división del trabajo, la educación patriótica, las fiestas populares, las consagraciones religiosas, las efemérides y los cantos nacionales, el culto a los símbolos de unidad y trascendencia y la construcción de la ciudad como una galería del progreso ${ }^{3}$.

De acuerdo a Lindon, sería la categoría de tiempo la que habría caracterizado al siglo XIX -en tanto expresión de la modernidad-, construida sobre una de sus ideas centrales: el "progreso", mientras que la época actual se caracterizaría particularmente por el papel que juega el espacio en la constitución de la vida social (187). Un aspecto importante de esta «conciencia temporal» es la convergencia de los lenguajes en matrices técnicas y, con ello, una cierta crisis de la autonomía de la representación artística. Las estrategias figurativas ponen en duda el realismo mimético producto de la interrelación entre los diversos medios visuales que modifican los reportorios clásicos con la irrupción de la vida cotidiana y su trazado urbano. Las imágenes organizan un continuo -útil a la reiteración de ideas hegemónicas- que dota de significado las relaciones sociales, pues «no vivimos en el interior de un vacío que cambia de color, vivimos en el interior de un conjunto de relaciones que determinan ubicaciones mutuamente irreductibles y en modo alguno superponibles» (Foucault 2).

De esta manera, nuestra constitución como individuos no solo se afianza de acuerdo a coordenadas temporales, "sino también en determinados territorios, que están cambiando, que son producto de historias» (Tapia 13). En ese sentido, las fotografías analizadas nos remiten al territorio inicial de ese Chile naciente, nos indican -tanto por lo que muestran como por lo que esconden- lo importante, lo deseable y lo correcto. ¿Cómo se organiza la sociedad chilena en la región específica?:

por un lado, consiste en la constitución de sujetos que configuran una vida política en su diversidad, en su articulación, pero a la vez (...) se realiza en determinados territorios

La articulación descrita es posible si la ciudad narra su acontecimiento y su cambio, por ello se volvió una práctica de la modernización realizar ferias mundiales, pabellones o exposiciones. Visualidad y monumento logran compaginar la heterogénea historia de la urbe y la comprimen en un conjunto de objetos, promesas y tecnologías «auráticas» que garantizan el desarrollo. En 1850 Manuel García de la Huerta promulga un decreto para la exhibición del arte chileno y en 1869 se inaugura la Exposición Nacional de Agricultura. Sin embargo, es en la década del setenta cuando el intendente Benjamín Vicuña Mackenna, quien asume la más radical remodelación urbanística de Santiago, construye un espacio de segregaciones sociales, eclecticismos arquitectónicos, urbanizaciones eléctricas, estetizaciones ciudadanas y controles policiales. El liberalismo conservador se apropia de la ciudad e inventa su fantasía urbanística. En 1872 se presenta la Exposición de Artes e Industrias o Exposición del Mercado, que destaca la ambigua alianza entre creación y producción, entendida como obra de la elite y retrato de su legitimación. 
(...) en los que se configuran un conjunto de estructuras e instituciones a través de las cuales se instituyen diferentes formas de vida política (14).

De esta manera se actualiza una opción de ordenamiento social, opción coherente con una visión colonial de desarrollo, propuesto, precisamente, desde los imperios coloniales: Inglaterra, Francia y, más adelante, Estados Unidos. El desafío es mayor entonces, puesto que la independencia trae consigo una serie de demandas que implican delimitar y trazar, en sentido literal y figurado, los límites y bordes del nuevo país. En sentido literal, se diseñan las nuevas ciudades, lo que implica un reposicionamiento de los actores y una centralidad creciente del centro urbano por sobre el ámbito rural. En sentido figurado, se reordenan las relaciones en un marco distinto, el nacionalista-democrático.

La democratización en América Latina, en general, ocurre como pugna indecisa entre distintas racionalidades. La democracia es resultado de la correlación de fuerzas y no de una razón producida por una praxis social común. Los nuevos estados latinoamericanos se afianzan en el mismo momento en que se consolida el modo de producción capitalista en Europa-Inglaterra (Lechner 2005). «El fenómeno no es sencillamente la interdependencia entre naciones o la multiplicidad de contactos entre ellas sino más bien la constitución de un espacio global unificado que implica relaciones asimétricas entre sus componentes» (Garretón et al. 39).

La población urbana en el Chile de 1813 era aproximadamente el 10\% de la población total del país, mientras que en 1920 constituía el 42,8\%, uno de los porcentajes más altos de América Latina debido, en gran medida,

a la urbanización de una parte del peonaje itinerante. (...) Antes de 1840, los asentamientos habitacionales del «bajo pueblo» eran extremadamente dispersos (...) después de 1860 en cambio, las habitaciones del «bajo pueblo» aparecían aglutinándose en torno y dentro de las grandes ciudades, configurando un fenómeno bastante visible (Salazar 232-3).

Hacerse cargo de ordenar estas nuevas ciudades no era una empresa cómoda al tratarse, en el nuevo contexto liberal-democrático, de personas «libres» a quienes debía otorgarse la garantía de su presencia y, a la vez, ubicarlas dentro de un patrón productivo que las definiera no solo en la escala social, sino también en la residencia: el lugar en el trabajo es sinónimo del lugar habitacional. La idea de urbe moderna asociada a estándares de bienestar y desplazamiento implicaba disciplinar a la población en el uso de los artefactos y discursos del desarrollo, incluirlos en la modernización y vigilarlos en las costumbres a través de distintos mecanismos. Uno de ellos fue la ejemplificación, es decir, mostrar masivamente las condiciones ejemplares de comportamiento intentando regular la vida cotidiana. Ello implicaba generar coordenadas para la observación y la atención pues las tecnologías visuales deterioraban las jerarquías, permitiendo, a los otros, ingresar a lo visual con exigencias de tolerancia cuestionables. En Chile, durante el siglo xix, se dio una batalla por las imágenes, pues traían consigo una lógica doble e irreconciliable: la 
invisibilización del otro cuyas carencias antropológicas y fisiognómicas delataban la falta de estilo y civilización, y la emergencia social de un sujeto histórico que pedía a lo visual reconocimiento de las memorias ausentes o destruidas por el Estado Nacional. Y aquí la fotografía podía servir de gran ayuda puesto que, como arte mecánica, sería la ficción de la modernidad, al ser el dispositivo tecnológico que permitiera romper las distancias e ingresar en una "maquinaria panóptica» (Virilio 4) que nos relaciona pero también nos controla. La fotografía permitió -a través de la anécdota- la circulación de prototipos nacionalistas establecidos en los ideales de belleza de las damas de sociedad, la austeridad patriarcal del hacendado, la rígida pose guerrera del oficial del Ejército que, en su conjunto, sintetizaban los modelos de lo público y privado indicando el sensible político a seguir. Las imágenes que registran los fotógrafos de la época desempeñan un rol mucho más integral en las prácticas culturales (Harvey 2008) puesto que, como ya lo hemos señalado, «en tales condiciones quedan incluidos papeles y modelos de conducta» (Balandier 15). Un momento de lo anterior lo describe la Exposición del Coloniaje, inaugurada el 17 de septiembre de 1873 en el Palacio de los Gobernadores, cuyo propósito era reconciliar las tendencias afrancesadas modernas con los tradicionales valores hispanos. La muestra tenía el propósito de consolidar el papel de las familias adineradas en la historia del país. Se exhibieron sus artículos cotidianos, estilos y genealogías como irrefutables documentos históricos del origen de la nación:

la exposición era una demostración pública de riqueza personal y ancestros ilustres. Sus muebles y cuadros, habían sido conceptualizados de nuevo como tesoros nacionales. La exposición también llevó al pueblo al salón para ver los lujos de una civilización pasada que podían reclamar como suya, ahora que era patrimonio nacional. La división social de clases se convirtió en la norma y dado el peso de precedente histórico, a través de la comparación entre la cultura material de la elite y la de la gente pobre. Las distinciones de género también fueron reforzadas, ya que todos los objetos 'femeninos' eran agrupados en una sola sala (Schell).

El ejercicio representacional de unir las retóricas nacionalistas con las visiones de orden social y la potestad de clase requirió una "pedagogía de la imagen, tan necesaria como lo fuera, en su momento, la de la lectura y la escritura, sobre la que se fundó la escuela republicana y con ella, la propia República» (Balandier 159-60).

\section{IMÁGENES HIPOSTÁSICAS}

El cristianismo es una de las más poderosas culturas visuales de Occidente. Los protocolos que ha creado para la circulación de las imágenes mantienen, con las transformaciones obvias, un protagonismo importante. La posibilidad de mostrar lo esencial en la multiplicación icónica, de hacer que el todo se presente en el fragmento o lo invisible anuncie su inconmensurable irrealidad en lo visible, son características que la modernidad intentó domesticar y traspasar a los dispositivos 
tecnológicos, creando una situación paradojal: la reunión en un solo proceso de una mirada histórica y una obra trascendental. La fotografía encontró en el uso social una demanda parecida: tenía que dar cuenta de un grupo que buscaba, en la imagen técnica, historizar su fortuna y mitificar su poder. El monoteísmo del capital revestía a las fotografías de un relato secularizador conducido por familias cristianas, pero su contenido era demasiado prosaico para justificar visiones de mundo y épicas fundacionales. La organización de Chile era el trabajo de hombres heroicos, cuya entereza moral e inteligencia piadosa los llevó a imaginar un suelo común. Encontrar una fórmula para conciliar el pasado filial y el presente urbano significó convertir a las ciudades en una vitrina de adelantos: la arquitectura materializaba los deseos liberales de orden y progreso ocupando el espacio con una monumentalidad que debía su apego jurídico al Estado centralizador borbónico. La ciudad de Santiago, en especial, fue diseñada para la vida política de hombres y mujeres que impusieron una racionalidad específica: consenso, equilibrio y reforma.

Las fotografías urbanas de la época privilegian el ordenamiento urbano de las nuevas ciudades (94 fotografías), sus fachadas y calles (88 fotografías) y su ordenamiento en torno a una plaza (51 fotografías) donde se sitúan las principales instituciones reguladoras: la Iglesia (20 fotografías), la Intendencia o Gobernación (38 fotografías) y los monumentos que van constituyéndose en hitos para recordar (22 fotografías).

Para emplear una imagen, podría decirse que mientras la ciudad patricia estaba urbanísticamente dominada y moralmente regida por sus iglesias, conventos y capillas, el suburbio campesino lo estaba por sus quintas, cañadas y chinganas. Este contraste envolvía, obviamente, una oposición, que se hizo más aguda a medida que ambos, el suburbio campesino y el centro comercial patricio, se expandían, el uno sobre el otro (Salazar 123).

La urbanización puesta en marcha se reflejaba en las estaciones de ferrocarril, puentes, carreteras, muelles y canales (22 fotografías) que, junto a las imágenes de riberas navegables (92 fotografías) intentan mostrar el dominio de la naturaleza en oposición a su irrupción en terremotos, maremotos e inundaciones (29 fotografías). Estas imágenes son coherentes con el desarrollo ya que «Las obras públicas durante el siglo XVIII consistían en la construcción ocasional de alguna iglesia, cárcel, fuerte, puente o camino. O bien, en la reparación de edificios públicos» (Salazar 239).

De esta manera, el diseño de la ciudad fue regulando la vida cotidiana y segmentando, espacialmente a sus pobladores. En este sentido, el que las villas fueran pobladas por los grandes terratenientes adquirió un significado específico puesto que su presencia "transformó las villas campesinas en una reproducción de los viejos pueblos de conquistadores: se situó la nobleza en los alrededores de la plaza, los mercaderes y artesanos en las calles intermedias y la gente pobre en los suburbios» (Salazar 52; énfasis original). La distribución espacial de los individuos expresaba la forma de gobernar de la época y de situar a los diferentes agentes sociales en 
áreas concretas y estables, ayudando a saber dónde se encontraban. Lo anterior es una muestra del papel que va jugando la visualidad en las funciones de vigilancia, al crear un diagrama reconocible de morada y circulación. Las transformaciones en curso también tenían su base en las modalidades económicas concretadas por la apertura comercial con sus exigencias de refacción y creación de infraestructura (caminos, puertos, ferrocarriles) y un flujo comercial que importó una serie de artefactos culturales ingresados a la vida cotidiana con mucha rapidez. En la minería y en el agro, las actividades económicas dispusieron de nuevos recursos, muchos de los cuales fueron dirigidos a satisfacer el derroche y el esnobismo de los núcleos de poder. Sin embargo, estos procesos contribuyeron a la aparición de nuevos referentes culturales, discursos sociales y niveles de consumo. La orientación comercial no solo fue el producto de necesidades de sobrevivencia, también incorporó la fuerza de un proceso de modernización que exigía un contrato con las imágenes, elemento novedoso y seccional para dar cuenta de su impulso y opción totalizante. La fotografía se transformó en la escena simbólica donde la ciudad se protegió de sus errores mediante la exhibición de sus mejores edificios y triunfos técnicos ante el desorden y el tumulto.

La orientación de estas toma-vistas insinúa una colonización del paisaje, el repliegue de su agreste presencia a las líneas precisas y calculadas de la razón humana. No es solo la imagen intentando someter la realidad a los parámetros de una ideología dominante, es una epistemología técnica: el positivismo que busca dominar la extrañeza del mundo con la exactitud del diccionario y la verificación de la imagen. La fotografía, entonces, confiere a la elite un don, la visibilidad de sus cuerpos transfigurados en una modernización histórica y representativa que intenta suturar las diversas escenas en ella contenidas. Por lo mismo, hay que establecer un corpus o gramática que enseñe la pose y el gesto diferenciador. El poder se ubica en una distancia, apartado de quienes son la base de la vida cotidiana. "Se erigen palacios, se exponen símbolos, se ejecutan rituales, se despliegan demostraciones públicas; como ocurría tanto en el pasado cercano como en el remoto» (Balandier 116). La fotografía construye una comunidad de iguales que refrendan en sus cuerpos, vestidos, animales, casas, juegos, intimidades, biografías, ceremonias, paseos, joyas y descansos la fisonomía de una sociedad donde se enfrentan una secularización iconográfica de las identidades, una moralización sexual de los deseos y una estetización patriarcal del poder.

El pensamiento y sentimiento de la comunidad no están anclados en sus miembros, sino que se encuentran indisolublemente involucrados al suelo donde se afincan. En el suelo de la comunidad, están erigidos, distribuidos, ocupados y transitados todos los elementos con los que se elabora el mundo común, porque el espacio construido y habitado se constituye un complejo relacional, una estructura comunicativa (Fernández 150). 
¿Por qué en una sociedad de iguales se acepta que unos pocos determinen la forma de vida de otros muchos? Esta pregunta nos remite a que «la política es el conflicto acerca del sentido del orden» (Lechner 28). En nuestro análisis, organizar la ciudad también es dirigir la vida cotidiana y, al hacerlo, materializar la hegemonía de un grupo social. El tipo propuesto es «un orden en perpetua búsqueda y construcción, un objeto de deseo nunca plenamente alcanzado pero, por su mismo carácter de proceso inacabado, capaz de movilizar de manera constante las energías políticas y la subjetividad de los individuos en situaciones colectivas» (Lechner 9-10), es decir de una promesa de orden que en el contexto histórico de una época de carencias y limitaciones aparece como un ideal de futuro compartido y deseado.

\section{INVISIBLES EN EL VALLE}

¿Y dónde estaba el pueblo? No debiese sorprender su ausencia en las fotografías. Si bien aparecen personas en ellas (en 156, mayoritariamente hombres), es algo circunstancial y permite realizar el contraste, magnificando la ciudad y sus obras. El pueblo, fuera de su presencia «regulada y controlada» en el comercio, «abarcó también la administración de los más populares (y lucrativos) establecimientos de diversión pública de la época: las 'chinganas'» (Salazar 93). Sin embargo, paulatinamente,

las autoridades nacionales y locales comenzaron a desalojar de las ciudades a los campesinos y el comercio campesino, jugándose por el desarrollo de la sociedad urbana y de los «comerciantes establecidos. [También] se reprimieron las manifestaciones socioculturales del «bajo pueblo» (que hacia 1830 era prácticamente el campesinado mismo) especialmente sus formas públicas de diversión y su moral privada. El objetivo era reorientar la sociedad popular conforme las pautas de la sociedad urbana (Salazar 119).

A partir de 1870 se desarrolló una política de planificación urbana destinada a implantar, sobre los arrabales peonales, el cuadrillado ajedrecístico-colonial de las calles y las fachadas de adobe y teja. Estas iniciativas fueron resistidas por los mercaderes, que pugnaban por mantener «la altísima concentración de miseria social por metro cuadrado de ciudad. La criatura que brotó de ese cruzamiento de escrúpulos urbanos e intereses mercantiles recibió un nombre especial: fueron los conventillos» (Salazar 238). La ciudad es la fuente de legitimidad de sus autores y aquellos que la habitan pertenecen a la comunidad, por esta causa, los sectores populares no tienen cabida ni en la ciudad ni en la imagen, pues viven en el periurbano: límite donde el estado de naturaleza los incita al desorden y el extravío. Las fotografías de ciudad, entonces, se reservan para la recreación de un tiempo ya consolidado, irreversible y central.

Las imágenes de la ciudad en el Chile inicial dan cuenta de la ideología dominante (Sontag 2006). Al ofrecer una carta de navegación para el desarrollo de la sociedad a partir de una promesa -una utopía- permiten: (a) la construcción de un orden 
social y; (b) la construcción de un nosotros. Las funciones políticas de las fotografías de este primer periodo son distintas de acuerdo a la clase social de los usuarios. En una primera etapa (1840-1860), la elite se muestra frente a sus pares y demuestra su capacidad de ordenamiento con las fotos de sus ciudades. Con la masificación de la fotografía el «pueblo» accede a ella, y al hacerlo también logra acceder a una cierta estética que es fundamentalmente política, puesto que los fotógrafos ya habían impuesto ciertas normas acerca de lo fotografiable de acuerdo a los modelos que ellos mismos habían traído desde el extranjero, los que fueron validados por la elite y asumidos como realidad por los restantes usuarios. De esta forma, la fotografía va expandiendo una cierta idea de ordenamiento social al modelar cuerpos y espacios.

\section{A MODO DE CIERRE}

La ciudad, en las imágenes revisadas, desfila frente a los ojos locales y foráneos mostrando el surgimiento de un país moderno y desarrollado, siendo entonces el progreso el horizonte de sentido, la promesa futura que proyecta la nación. La vida cotidiana, por tanto, debe adaptarse a este nuevo esquema, lo que implica controlar el tiempo y el espacio. El tiempo en virtud de la lógica de la producción, es decir, se intenta administrar y ordenar los cuerpos en función de las necesidades de las industrias nacientes. El espacio en cuanto al ordenamiento geográfico de la ciudad, el diseño de las calles, la construcción de puentes, la planificación urbana que deja en los arrabales al "pueblo», que esconde la miseria y muestra la opulencia de una clase.

Las fotografías de la ciudad muestran, de manera evidente, todo aquello de lo cual la elite está orgullosa. Se pone en evidencia y se inmortalizan los procesos de independencia a partir de la exhibición de los monumentos y la construcción de mitos heroicos, la organización de la sociedad a partir de una lógica nacionalistademocrática con la exhibición de instituciones modernas como las fachadas de escuelas y ministerios, y el progreso que se traduce visualmente como la domesticación de la naturaleza reflejada en puentes, industrias, muelles y riberas navegables. La fotografía cumple la hazaña civilizatoria de trasladar el tiempo colonial y alterar su código con las imágenes de una sociedad satisfecha de su historia y complacida de su modernidad.

\section{REFERENCIAS}

Balandier, Georges. El poder en escenas. De la representación del poder al poder de la representación. Buenos Aires: Paidós Studio, 1994. Medio impreso.

Crary, Jonathan. Las técnicas del observador. Visión y modernidad en el siglo XIX. Madrid: Cendeac, 2008. Medio impreso.

Cid, Gabriel y Alejandro San Francisco (eds.). Nación y Nacionalismo en Chile. Siglo XIX. Vol. 1. Santiago: Centro de Estudios Bicentenario, 2009. Medio impreso. 
Fernández, Pablo. «El territorio instantáneo de la comunidad posmoderna». La vida cotidiana y su espacio-temporalidad. Coord. Alicia Lindon. Barcelona: Anthropos, 2000. 147-170. Medio impreso.

Foucault, Michel. Des espaces autres. Trad. Luis Gayo Pérez Bueno. Astrágalo 7 (1997). 1-6. Medio impreso.

Harvey, David. La condición de la posmodernidad. Madrid: Amorroutu, 2008. Medio impreso.

Garretón, Manuel Antonio et al. América Latina en el siglo XXI. Hacia una nueva matriz sociopolítica. Santiago: LOM Ediciones, 2004. Medio impreso.

Lechner, Norbert. Obras escogidas. Santiago: LOM Ediciones, 2005. Medio impreso.

Lindón, Alicia. "La espacialidad como fuente de las innovaciones de la vida cotidiana. Hacia modos de vida cuasi fijos en el espacio». La vida cotidiana y su espaciotemporalidad. Coord. Alicia Lindon. Barcelona: Anthropos, 2000. 187-209. Medio impreso.

Reguillo, Rossana. «La clandestina centralidad de la vida cotidiana». La vida cotidiana y su espacio-temporalidad. Coord. Alicia Lindon. Barcelona: Anthropos, 2000. 77-93. Medio impreso.

Rodríguez Villegas, Hernán. Historia de la fotografía. Fotógrafos en Chile durante el siglo XIX. Santiago: Centro Nacional del Patrimonio Fotográfico / Editora Ograma, 2001. Medio impreso.

Salazar, Gabriel. Labradores, peones y proletarios. Santiago: LOM Ediciones, 2000. Medio impreso.

Schell, Patience. Desenterrando el Futuro con el pasado en Mente. Relics and Selves, Iberoamerican Museum of Visual Culture on the web. Birkbeck College. «http:// bit.ly/TZL1Ta». Sitio web.

Salvador, Juan. «Las tensiones espacio-temporales de la vida cotidiana». La vida cotidiana y su espacio-temporalidad. Coord. Alicia Lindon. Barcelona: Anthropos, 2000. 123-146. Medio impreso.

Stephan, Beatriz y Jens Andermann. Las galerías del progreso. Museo, exposiciones y cultura visual en América Latina. Buenos Aires: Beatriz Viterbo Editora, 2006. Medio impreso.

Sontag, Susan. Sobre la fotografía. México: Santillana Ediciones Generales, 2006. Medio impreso.

Tagg, John. El peso de la representación. Barcelona: Editorial Gustavo Gili, 2005. Medio impreso.

Tapia, Luis. Pensando la democracia geopolíticamente. La Paz: CLACSO / Muela del Diablo Editores, 2009. Medio impreso.

Véliz, Claudio. «La mesa de tres patas». Desarrollo Económico Vol. III: 1-2 (1963). 1-18. Medio impreso.

Virilio, Paul. «Fin de l'histoire, ou fin de la géographie? Un monde surexposé». Le Monde Diplomatique (1997). 17-21. Medio impreso. 